\section{Correlation of Fractal Dimension with Histomorphometry in Maxillary Sinus Lifting Using Autogenous Bone Graft}

\author{
Rafael Scaf de Molon ${ }^{1}$, Wagner Nunes de Paula ${ }^{1}$, Rubens Spin-Neto ${ }^{2}$, Mario \\ Henrique Arruda Verzola ${ }^{1}$, Guilherme Monteiro Tosoni', Raphael Carlos \\ Comelli Lia ${ }^{2}$, Gulnara Scaf ${ }^{1}$, Elcio Marcantonio Jr ${ }^{1}$
}

\author{
'Department of Diagnosis and \\ Surgery, Araraquara Dental \\ School, UNESP - Univ Estadual \\ Paulista, Araraquara, SP, Brazil \\ ${ }^{2}$ Oral Radiology, Department \\ of Dentistry, Aarhus University, \\ Aarhus, Denmark \\ ${ }^{3}$ Department of Physiology and \\ Pathology, Araraquara Dental \\ School, UNESP - Univ Estadual \\ Paulista, Araraquara, SP, Brazil- \\ Correspondence: Prof. Dr. Elcio \\ Marcantonio Jr., Rua Humaitá, \\ 1680, 14801-903 Araraquara, SP, \\ Brasil. Tel.: +55-16-3301-6378.
}

\section{e-mail: elciojr@foar.unesp.br}

\begin{abstract}
The aim of this study was to determine the pattern of bone remodeling after maxillary sinus lifting in humans by means of fractal dimension (FD) and histomorphometric analysis. Therefore, the correlation between FD and the histomorphometric findings was evaluated. Sixteen patients with posterior edentulous maxilla were enrolled in this study. Maxillary sinus lifting was performed using autogenous bone grafted from the mandibular retromolar area. Three direct digital panoramic radiographs were obtained: before surgery (Group 1), immediately postoperatively (Group 2) and after 6 months of healing (Group 3) for FD analysis. Biopsies were taken after 6 months, processed and submitted to histological and histomorphometric analysis. Data were analyzed by Shapiro-Wilk test and ANOVA test followed by a Tukey test $(\alpha=0.05)$. The bone volume fraction of newly trabecular bone (TB) and medullary area (MA) was measured as $62.75 \% \pm 17.16 \%$ and $37.25 \pm 17.16 \%$, respectively. Significant difference in FD analysis was measured between Group 1 and Group 3. No significant difference was found in the correlation between $\mathrm{FD}$ and histomorphometric analysis for TB and MA ( $p=0.84)$. In conclusion, all performed analyses were effective in assessing the bone-remodeling pattern in the maxillary sinus, offering complementary information about healing and predictable outcomes. There were no correlations between FD and histomorphometric analysis.
\end{abstract}

\section{Introduction}

The use of osseointegrated implants is a widely used procedure to restore the functional and aesthetic of the patients, with a high survival rate. However, alveolar bone resorption after tooth extraction, and/or pneumatization of the maxillary sinus, result in insufficient horizontal and vertical bone dimension for the implant placement in an ideal three-dimensional position (1). Sinus lift, firstly described by Boyne and James (2), is a surgical approach that enables the placement of appropriate length implants due to the elevation of the sinus membrane from the maxillary sinus, allowing the interposition of bone grafts, increasing the bone height in the posterior edentulous maxilla (3) for the long term implant stability.

Surgical procedures for sinus lifting floor are commonly performed using autogenous bone grafts and/or bone substitutes. Autogenous bone graft still represents the gold standard for grafting materials especially due to its osteogenic, osteoinductive and osteoconductive characteristics as shown in a recent study (4). Bone quality and volume in maxillary sinus are a major determinant of implant prognosis (5) and thus, its evaluation is important to the appropriate treatment plan. Esposito et al. (6), showed that low bone quality as one of the most important factors associated with oral implant failures due to biological causes. Therefore, preoperative bone quality assessment is important for oral implant surgery planning. A previous study (7) evaluated by histomorphometry the trabecular bone quality in the posterior maxilla, and showed lower trabecular bone number, connectivity and volume compared to the anterior maxillae. Thus, evaluating the bone architecture in posterior maxillae is fundamental to choose the length of the healing period that is suitable for implant rehabilitation.

Currently, many techniques have been established in order to evaluate the bone quality and to quantitatively characterize structural changes of bone at sites for future implant placement, such as histological $(1,4)$, computed tomography (CT) (8), cone-beam CT (9), and fractal dimension (FD) analysis $(10,11)$. Among these, $F D$ analysis has been introduced as an accurate, easily available and economical method (12). FD is a technique for quantitative and texture evaluation of geometric structures that exhibit patterns through the image (13), which received particular attention for application in panoramic (14-17) and periapical radiographs $(18,19)$. The structure is characterized by a single number, the fractal dimension, which is calculated with a computer algorithm (13). FD is commonly used in non-standardized radiographs, to evaluate and quantify a cancellous bone structure for the detection 
of bone changes (20), apical healing (21), periapical bone (22), and systemic conditions such as osteoporosis $(23,24)$. FD analysis uses a box-counting algorithm to quantify the trabecular bone pattern through counting the bone marrow and trabecular bone interface and also to access the trabecular and medullar bone boundary (25). In this method, when a higher box counting value is reached, more complex is the bone structure.

To the best of our knowledge, this is the first clinical study that compared the fractal dimensional analysis with the histomorphometric parameters to determine the bone graft-remodeling pattern from the moment of the grafting procedure until the moment of implant installation. Thus, the aim of this study was to determine the pattern of bone remodeling after maxillary sinus lifting in humans by means of fractal dimension (FD) and histomorphometric analysis. Therefore, the correlation between FD and the histomorphometric findings was evaluated.

\section{Material and Methods}

\section{Study Population}

The study protocol was conducted according to the principles outlined in the Declaration of Helsinki (last recruited at the Department of Periodontology. The inclusion criteria involved patients requiring unilateral sinus floor augmentation with a residual alveolar bone crest height of 2-5 mm (based on panoramic images), absence of systemic conditions such as diabetes mellitus, sinus infection or alveolar bone lesions, and non-smokers. The patients were fully informed about the treatment and a written informed consent was obtained prior to commencement of treatment. These patients underwent panoramic radiographs in three stages of treatment: preoperative (Group 1 - G1), immediately postoperative after sinus lifting and bone grafting (Group 2 - G2), and 6 months postoperative (Group 3 - G3).

\section{Autogenous Bone Grafting}

Prior to the sinus lifting surgery, conventional panoramic radiography was performed to evaluate the maxillary sinus and the residual vertical bone height ( $\mathrm{G} 1$ ). To obtain the bone graft from the mandibular angle, the procedure was performed under local anesthesia (Mepivacaine 2\% and Epinephrine 1:100.000; DFL, Rio de Janeiro, RJ, Brazil). To harvest the mandibular bone, an access preparation was carried out with a crestal and vertical releasing incision in the retromolar region. Then, a mucoperiosteal flap was obtained by exposing the buccal wall and the oblique line. The osteotomy was performed with rotating instruments and the cortical block was obtained with a hammer and chisel. The mucoperiosteal flap was repositioned and the defect was sutured with Vicryl 4-0 thread (Ethicon; Johnson \&t Johnson SA, São Paulo, SP, Brazil). The graft was kept until its use in sterile saline solution.

\section{Sinus Lifting Procedure}

Under local anesthesia, a crestal incision in the maxillary edentulous area followed by two vertical incisions extended both mesial and distal to the sinus lateral wall was performed. The mucoperiosteal flap was detached to full exposure the maxillary lateral sinus wall. A lateral window approach was performed, the cortical bone wall was detached and the Schneiderian membrane was elevated, with the aid of special curettes (Hu-Friedy, Chicago, IL, USA). The autogenous bone graft was particulate using a bone mill (Neodent, Curitiba, PR, Brazil) and was inserted up to the sinus wall (Figs. 1A and 1B). The flaps were repositioned and sutured with Vicryl 4-0 thread. Immediately after the surgical procedure, a postoperative panoramic radiography was performed (G2). All patients received post-operative instructions, oral antibiotics (amoxicillin, $500 \mathrm{mg}$ ) and oral anti-inflammatory (mimesulide, $100 \mathrm{mg}$ ). The sutures were removed 10 days after the surgical procedure, and the area remained without influence of direct load during the entire bone regeneration phase.

\section{Biopsy Harvesting}

Six months after sinus floor augmentation a panoramic radiography was taken (G3). Then, bone biopsies were harvested with a trephine bur (Trephine Burr, $2.0 \mathrm{~mm}$ diameter, $13 \mathrm{~mm}$ long; 3i Implant Innovations, Inc., Palm Beach Gardens, FL, USA) during implant site preparation. One bone biopsy cylinder was obtained and the trephine sites were used for implant placement (Figs. 1C and 1D). The biopsy involved the residual maxillary bone and augmented sinus (bone graft), and preparation depth was defined from the planned implant length.

The biopsy samples were stored in 10\% buffered formaldehyde solution for 3 days to preserve the structures to be evaluated. Thereafter, the biopsy samples were processed for decalcified section preparation by immersion in a decalcification Morse solution (1:1 sodium citrate $20 \%$ + formic acid 50\%) for 5 to 6 weeks at room temperature (with 3 solution changes per week) and were then embedded in paraffin. Serial section of $6-\mu \mathrm{m}$ thickness were obtained using an automatic microtome (Jung Supercut 2065, Leica Instruments $\mathrm{GmbH}$, Heidelberg, Germany), mounted on slides and stained with hematoxylin and eosin (H/E). 


\section{Histological and Histomorphometric Analysis}

The histological evaluation was made using an optical microscope (Diastar; Leica microsystems $\mathrm{GmbH}$, Wetzlar, Germany) at 100x magnification. Images were selected and transferred to a computer display through a digital camera (DFC-300-FX, Leica microsystems $\mathrm{GmbH}$ ) attached to the optical microscope allowing histomorphometric measurements and histological descriptive analysis.

A blinded and calibrated examiner performed the descriptive histological and histomorphometric analysis. The digital images of histological slides were imported and analyzed into the program Image Tool for Windows
(UTHSCSA, version 3.00, San Antonio, CA, USA). For the descriptive histological analysis, the parameters evaluated were: the type and the quality of newly formed bone, pattern of bone remodeling, bone graft reaction, and inflammatory reaction

The histomorphometric analysis was made to directly measure the percentage of bone formation 6 months after sinus floor augmentation. Selected cuts for histomorphometric analysis followed the semi-series standard: the first section of the first slide was selected, and then four sections sequencing were despised and so on. Ten sections were evaluated from each specimen.
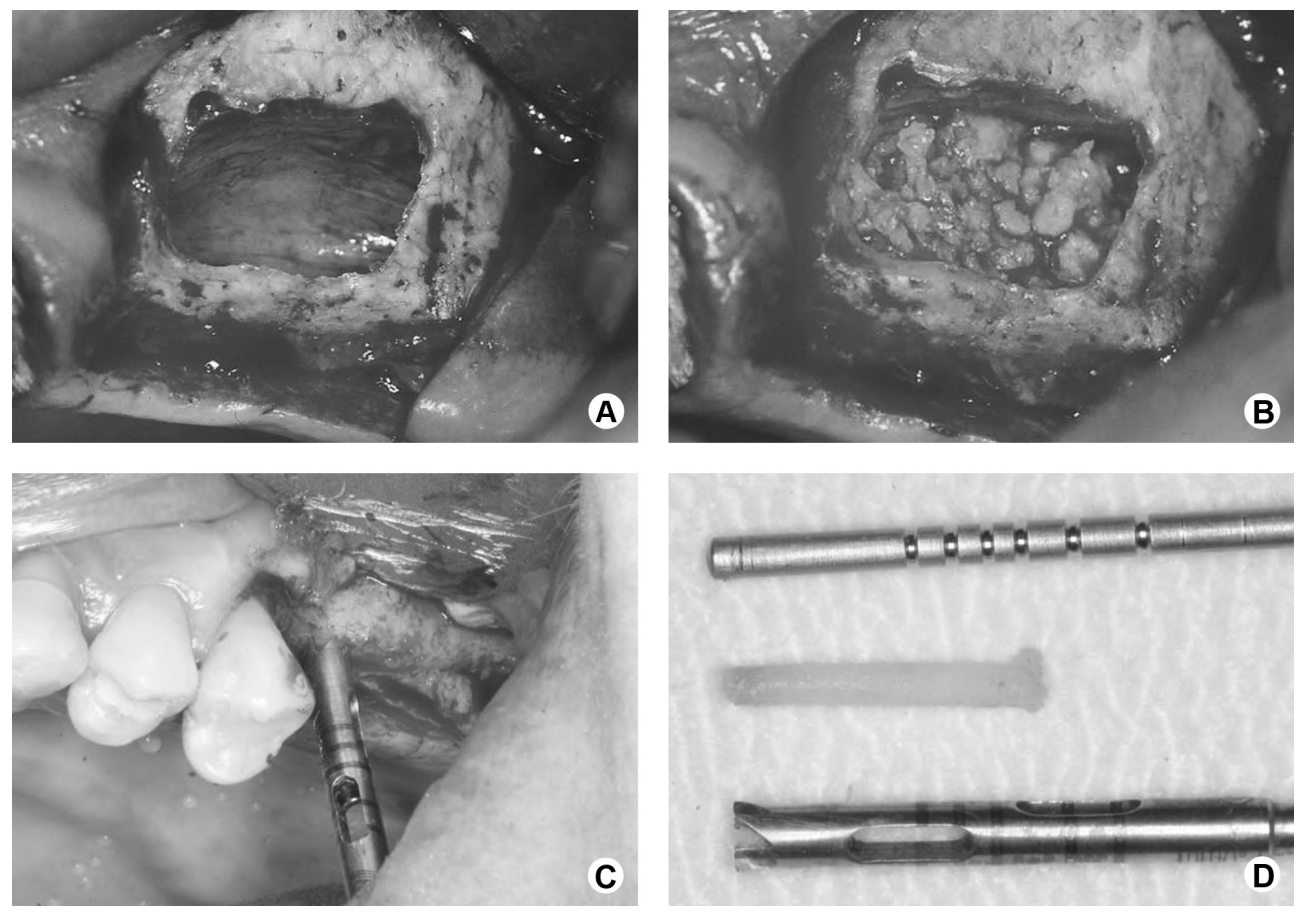

Figure 1. A and B: Clinical procedure for sinus floor augmentation using a lateral window approach and autogenous bone graft harvested from the mandibular retromolar area. C and D: Bone biopsy harvested 6 months after the sinus lift procedure and the trephine sites were used for implant placement.


Figure 2. Representative images of the bone biopsy showing the area of interest that was represented by the whole grid (26 mm x $38 \mathrm{~mm})$, which was positioned from the reversal line, disregarding $1 \mathrm{~mm}$ of distance in direction to the newly formed bone. 
Using image managing/editor software (Adobe Photoshop, Adobe Systems Incorporated, San Jose, CA, USA) a grid of $26 \mathrm{~mm} \times 38 \mathrm{~mm}$ was constructed and overlaid on the digital images obtained from the histological sections. The area of interest was represented by the whole grid, which was positioned from the reversal line, disregarding $1 \mathrm{~mm}$ of distance in direction to the newly formed bone (Fig. 2). Using dedicated software (Image Tool, UTHSCSA ImageTool), the areas occupied by the trabecular bone (TB) and medullary area (MA) were measured separately. Thus, it was measured the percentage of space occupied by the two structures, in relation to its newly formed area.

\section{Radiographic Examination}

For radiographic examination, the three panoramic radiographs were taken with the Ortophantomographic $\mathrm{OP}$ 100 equipment (Instrumentarium Image, DenOptix Digital Imaging System; Dentsply Gendex, Des Plaines, IL, USA) set to $70 \mathrm{kVp}$ and $6 \mathrm{~mA}$. Using image J software (http://rsb. info.nih.gov/ij/index.html; version 1.36b / NIH software), a region of interest (ROI) was created and saved and set to a width of 64 pixels and a height of 56 pixels. Then, the three panoramic radiographs were superimposed to facilitate the positioning of the ROI. After the ROI selection on each radiographic image, the image was transformed into binary adjusting the threshold corresponding to the median of the histogram (Fig. 3). The images of the ROI (s), transformed into binary were saved in BMP (Bitmap Image File) for subsequent fractal dimension analysis.

\section{Fractal Dimension Analysis}

Fractal dimension analysis was calculated by the box-counting method using Benoit 1.3 software (Trusoft International Inc, St. Petersburg, FL, USA) as follows: If $\mathrm{S}=$ $\log$ (number of windows) $x \log$ (window size) then $F D=(1-S)$. This method splits the image into small self-similar images. These small binary images, calculates a mathematical formula that generate fractals values between 1 and 2, in which 1 corresponds to the value of a substantially uniform structure in a predetermined fixed space. When the fractal dimension is 2, the biological structure occupies all the available space of a region with a predetermined area.

\section{Data Analysis}

Statistical analysis was performed using specific software (GraphPad Software Inc., San Diego, CA, USA). Shapiro-Wilk test was used to assess whether data respected the theorem of the central distribution. The results showed that the data distribution was normal, and then parametric tests were used for analysis. To evaluate the differences between the periods, was used the one-way analysis of variance followed by a post-test of multiple comparisons
Tukey's test with a 5\% significance level. Histomorphometric data were expressed as means and standard deviation of trabecular bone and medullary area. Pearson's correlation was performed to assess the behavior of histomorphometric data of trabecular bone and medullary area in relation to the fractal dimension data. This evaluation compared the data of fractal analysis after 180 days, same period that the biopsy was removed.

\section{Results}

\section{Descriptive Histologic Analysis}

In the descriptive histologic analysis it was observed characteristics of trabecular bone, in varying quantity through the sections (Figs. 4A and 4B). In some regions, the calcified bone tissue is augmented, with marrow space
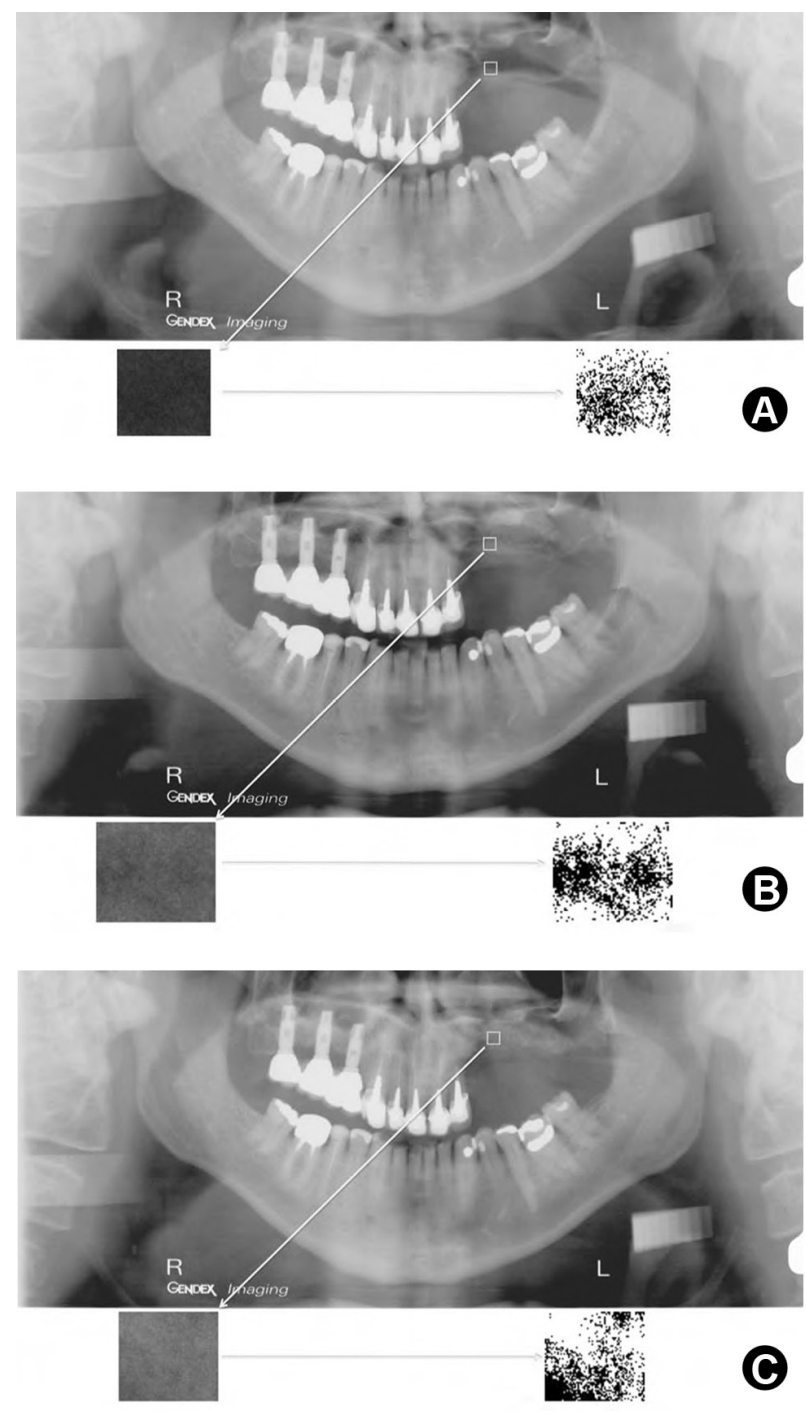

Figure 3. Panoramic radiographic examination: A: Before sinus lifting; B: Immediately after the sinus floor augmentation; C: 6 months after surgery. Images show the region of interest that was transformed into binary images adjusting the threshold corresponding to the median of the histogram for subsequent fractal dimension analysis. 
reduction. The distribution of osteoblasts on trabecular bone is random. Elongated pattern of osteoblasts are predominant, with fewer polyhedral osteoblasts (Figs. 4C and $4 \mathrm{D}$ ). In regions where there are polyhedral osteoblasts there is greater bone tissue apposition due to the greater functional activity.

The newly formed bone showed incremental lines that characterize the active bone formation in the process of bone turnover, suggesting the continuing tissue remodeling and formation, which characterizes active bone tissue (Fig $4 \mathrm{E})$. The autogenous bone graft inserted in the maxillary sinus is mostly integrated into the region. This interaction occurs through bone apposition on the surface of the graft particles, which in many instances are completely involved by the bone increment lines. The newly formed bone tissues were concentrically arranged, forming Havers channels, a feature of mature bone, including randomly arranged osteocytes with osteoblasts surrounding the tissue, consistently disposed amid osteoclasts (Fig. 4F). No inflammatory process was observed.

\section{Histomorphometric Analysis}

The mean and standard deviations of the percentage of bone filling for trabecular bone and medullary area 6 months after sinus lift and bone graft were $62.75 \pm 17.16 \%$ for trabecular bone (TB) and $37.25 \pm 17.16 \%$ for medullar area (MA). These results were significantly different from each other $(p<0.05)$.

\section{Fractal Dimension Analysis}

Mean value of fractal dimension in the first period was statistically significant compared to the third period $(p<0.05)$. Comparison between second and third period were not significant (Fig 5).
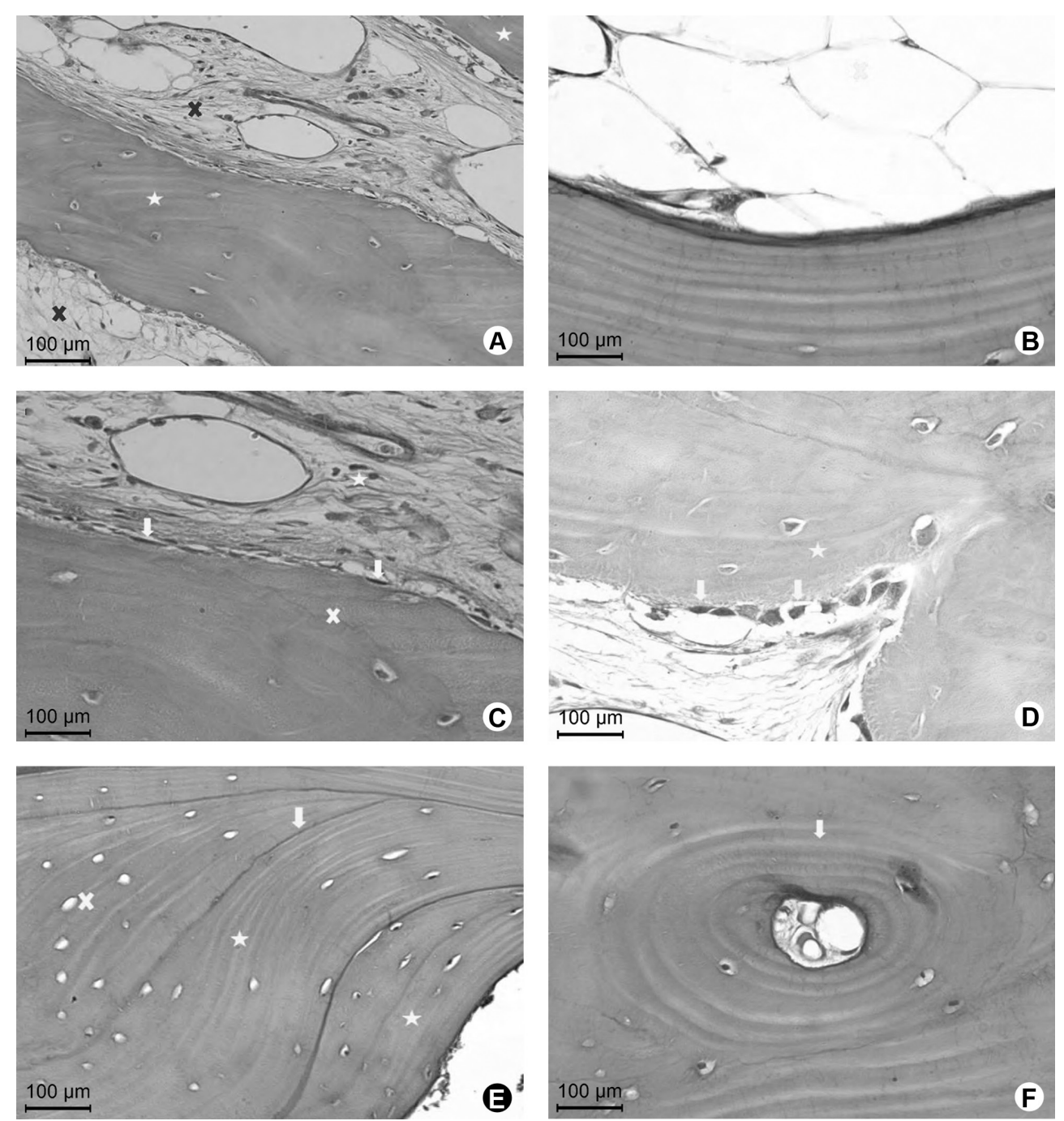

Figure 4. Histological cuts of the bone biopsy stained with hematoxylin and eosin showing: A: X: medullary area between the trabecular bone; trabecular bone showing osteocytes cells (20x magnification); B: Histologic cut at 40x magnification showing predominance of adipose tissue in the medullary area; C: New bone formed: arrow: elongated bone osteoblasts, mineralized connective tissue, X: reversal line in the process of bone formation; D: Arrow: polyhedral osteoblasts, region of bone apposition (40×); E: Arrow: reversal lines, incremental bone region, X: regions of osteoblasts; F: Harvers channel. 


\section{Correlation between Fractal Dimension and Histomorphometry}

Pearson correlation analysis, comparing the percentage of trabecular bone (TB) and medullary area (MA) with the fractal dimension showed no correlation between fractal dimension and histomorphometry for TB $(0.05, p=0.84)$ and MA (0.05, $p=0.84)$ (Fig. 6).

\section{Discussion}

One of the most important determinants to the clinical success of dental implants is the bone quality (5). There are several methods to evaluate the bone quality, among them: histological, CT and FD analysis. However, due to the high cost and high radiation dose, the use of CT is limited. FD is a sensitive method of image texture analysis (13), which can predict the quality of trabecular bone from 2D radiographies with low doses of radiation (11). Here, we evaluated for the first time the pattern of bone remodeling in sinus lifting in human biopsies, using autogenous bone graft by means of

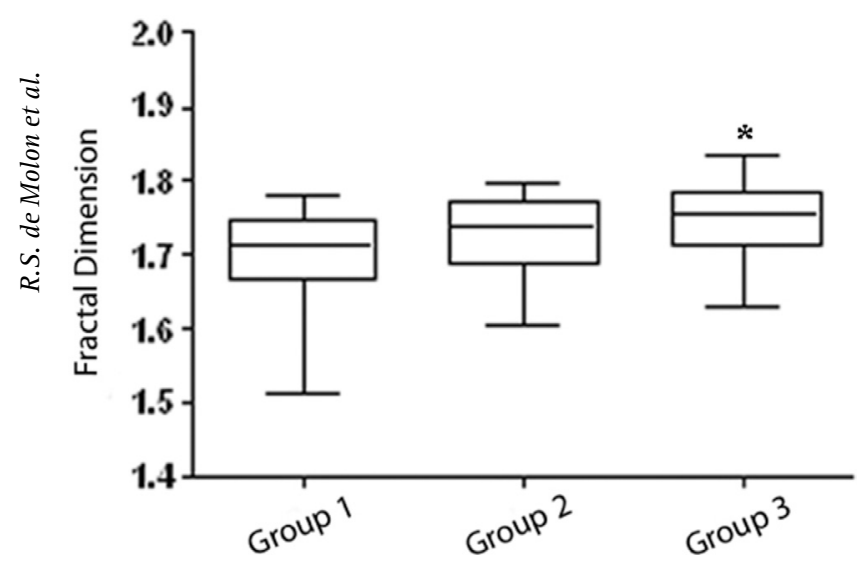

Figure 5. Mean, median and standard deviation of fractal dimension analysis among groups 1,2 and $3 .{ }^{*}$ Significant difference related to group 1. Shapiro-Wilk and ANOVA followed by a Tukey's test at 5\% significant level.
FD and histological analysis. Nevertheless, we used digital panoramic radiographic because this method is still the most used method to implant evaluation, planning, treatment and follow-up. Also, digital panoramic images have been used in other studies of FD (12,14-16), however not in bone graft regions.

The results of the present study showed that FD analysis, 6 months after the maxillary sinus lifting, presents the higher FD value due to the active bone remodeling, but the difference between the FD value between $\mathrm{G} 2$ and $\mathrm{G} 3$ was not significant. Histomorphometric analysis showed that maxillary sinus grafted presented approximately $63 \%$ of trabecular bone and 37\% of medullar area. On the other hand, there was not correlation between FD and histomorphometric parameters. It is not possible to compare the results of this study to others in the scientific literature, because this is the first study evaluating the effectiveness of FD to determine the bone-remodeling pattern in three different periods, using digital panoramic radiography and box-counting method.

Our descriptive histological analysis showed a very active bone remodeling, with incremental lines and regions of bone resorption, changing the direction of collagen bundles from both autogenous bone particles as the residual maxillary bone. This situation corresponds to the higher values of the FD analysis of G3, probably because of the remodeled bone and its trabecular pattern, characteristic of a posterior maxillary region. On the other hand, Heo et al. (12) evaluated the FD measured after sagittal split osteotomy at different time periods using digital panoramic and box-counting method. They found no significant difference in FD of alveolar bone before surgery or after a healing period. These results suggest that FD reproduces the complexity of trabecular bone morphology during the osseous healing (12).

The histomorphometric analysis was performed to differentiate only the trabecular bone (TB) and medullar
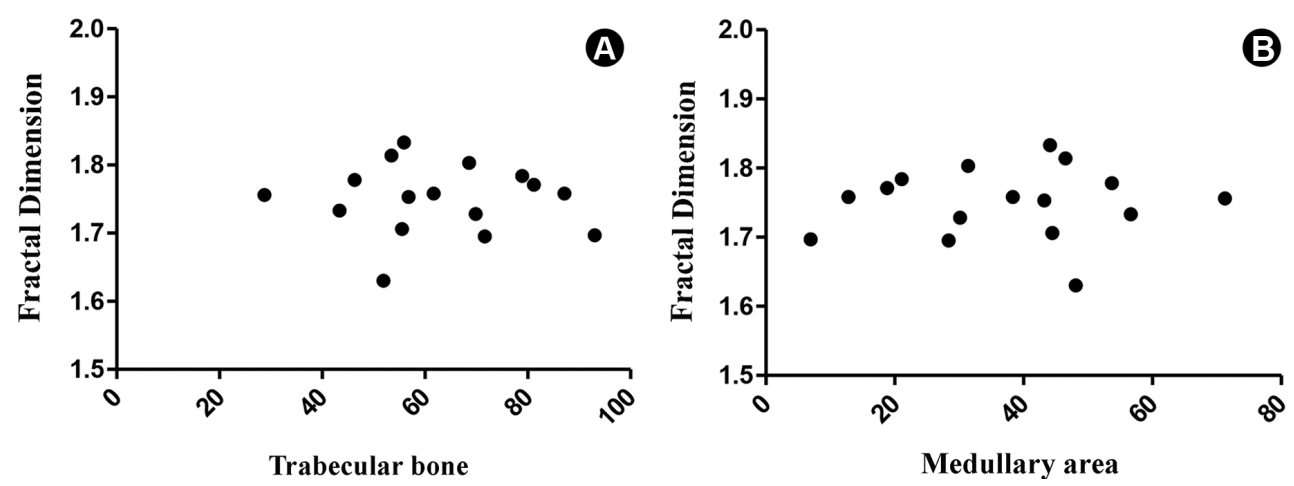

Figure 6. Correlation between fractal analysis and histomorphometric parameters for trabecular bone and medullary area after 6 months of sinus floor augmentation. No significant correlation was found using a Pearson's correlation. 
area (MA) because radiographic image data provides only differences in radiopacity between the trabecular bone and marrow space. Thus, the sensitivity of FD analysis could correspond to histomorphometry performed. Trabecular bone represented $62.75 \pm 17.16 \%$ of the total sample, although the marrow space had $37.25 \pm 17.16 \%$. The percentage of TB consisted mainly by newly formed bone, with characteristics of mature bone under active remodeling and neoformation. The MA was primary composed of medullary spaces, nervous fibers, blood vessels and bone cells. These results show that there was an adequate amount of newly formed bone with adequate amount of medullary space, what is expected of a good quality bone.

The FD analysis has the ability to assess the complexity of the images. When evaluating autogenous bone graft in the maxillary sinus, 6 months after surgery, by means of $F D$, we may suggest that the bone has a trabecular pattern varying in its complexity according to the different regions. The results of FD in this study showed that on $\mathrm{G} 1$ $(1.691 \pm 0.080)$ the $F D$ value was lower compared to the $G 2$ and $G 3$, because the regions analyzed were composed by an overlapping of the buccal cortical bone with the empty space of the maxillary sinus. Therefore, as the maxillary sinus was empty and the buccal bone was formed by a thin cortical, the image was represented by a low complexity. On the other hand, after the placement of particulate autogenous bone graft into the maxillary sinus, the values of FD (G2) were increased $(1.727 \pm 0.054)$. This result can be justified because the particulate bone graft possess in their format, portions of cortical bone with marrow spaces. Furthermore, among the particles of the graft, there was a considerable amount of empty spaces. The results of the


in relation to $\mathrm{G} 2$, but this difference was not statistically significant. The explanation for this result is probably the insufficient time to complete the bone graft remodeling. However, on $\mathrm{G} 3$, the bone structure presented an increased amount of mineralized tissue due to the apposition of new bone formation that was statistically significant in comparison to the G1. Possibly, in FD analysis of bone graft in maxillary sinus, it is necessary longer follow-up after sinus augmentation, to demonstrate significant difference between $\mathrm{G} 2$ and $\mathrm{G} 3$.

The correlation between FD and histomorphometry on $\mathrm{G} 3$ showed that there was not a strong correlation between these dates. However, the weak correlation can probably occur because there was no correlation between the size and placement of the selected area between the biopsy and the FD. Reassessing the methodology employed in this study, perhaps a radiographic examination of the biopsy obtained, would result in a FD that could be correlated with histomorphometric analysis of the same sample. However, up to the present date, there were not any studies correlating FD and bone histomorphometry.

In conclusion, our results showed all performed analysis were effective in assessing the bone-remodeling pattern in the maxillary sinus, offering complementary information about healing and predictable outcomes. FD method in digital panoramic images may be a reliable method for quantitative evaluation of bone remodeling pattern prior to implant installation after maxillary sinus lifting. There is no correlation between FD and histomorphometric analysis in a 6 months follow up period. Longer follow-up periods should be studied in order to test if a difference could be determined.

\section{Resumo}

0 objetivo deste estudo foi determinar o padrão de remodelação óssea após levantamento de seio maxilar in humanos por meio de analise de dimensão fractal (FD) e histomorfometria. Além disso, a correlação entre FD e histomorfometria foi avaliada. Dezesseis pacientes com edentulismo na região posterior da maxila foram relacionados para este estudo. Levantamento de seio maxilar foi realizado utilizando-se enxerto de osso autógeno coletado da região retro molar da mandibula. Três radiografias panorâmicas digitais foram obtidas: antes da cirurgia (Grupo 1), imediatamente após o levantamento de seio (Grupo 2) e após 6 meses de cicatrização (Grupo 3) para analise de FD. Biopsias foram coletadas após 6 meses, processadas e submetidas para analise histológica e histomorfométrica. Os dados foram analisados utilizando-se o teste Shapiro-Wilk e ANOVA seguido pelo pós teste de Tukey $(\alpha=0.05)$. A fração de volume de ósseo neoformado para o osso trabecular (TB) e para a área medular (MA) foi mensurado como $65,75 \% \pm 17,16 \%$ and $37,25 \pm 17,16 \%$, respectivamente. Diferença significante na analise FD foi observada entre os grupos 1 e 3 . Nenhuma diferença estatística foi encontrada para correlação entre FD e histomorfometria para TB e MA ( $p=0,84)$. Em conclusão, todas as análises realizadas foram efetivas em acessar o padrão de remodelação ósseo no seio maxilar, oferecendo informações complementares sobre cicatrização e previsibilidade de resultados. Não houve correlação entre FD e histomorfometria.

\section{Acknowledgements}

The authors are grateful to The São Paulo State Research Foundation (FAPESP) for the financial support (\#08/00795-5).

\section{References}

1. Stavropoulos A, Becker J, Capsius B, Acil Y, Wagner W, Terheyden H. Histological evaluation of maxillary sinus floor augmentation with recombinant human growth and differentiation factor-5-coated betatricalcium phosphate: results of a multicenter randomized clinical trial. J Clin Periodontol 2011;38:966-974.

2. Boyne PJ, James RA. Grafting of the maxillary sinus floor with autogenous marrow and bone. J Oral Surg 1980;38:613-616.

3. Trindade-Suedam IK, Morais JA, Faeda RS, Leite FR, Tosoni GM, Neto $C B$, et al.. Bioglass associated with leukocyte-poor platelet-rich plasma in the rabbit maxillary sinus: histomorphometric, densitometric, and fractal analysis. J Oral Implantol 2010;36:333-343.

4. Schmitt CM, Doering $H$, Schmidt $T$, Lutz $R$, Neukam FW, Schlegel $K A$. Histological results after maxillary sinus augmentation with Straumann ${ }^{\circledast}$ BoneCeramic, Bio-Oss ${ }^{\oplus}$, Puros ${ }^{\oplus}$, and autologous bone. A randomized controlled clinical trial. Clin Oral Implants Res 2013;24:576-585.

5. Esposito M, Hirsch JM, Lekholm U, Thomsen P. Biological factors 
contributing to failures of osseointegrated oral implants. (I). Success criteria and epidemiology. Eur J Oral Sci 1998;106:527-551.

6. Esposito M, Hirsch JM, Lekholm U, Thomsen P. Biological factors contributing to failures of osseointegrated oral implants. (II). Etiopathogenesis. Eur J Oral Sci 1998;106:721-764.

7. Ulm C, Kneissel M, Schedle A, Solar P, Matejka M, Schneider B, et al.. Characteristic features of trabecular bone in edentulous maxillae. Clin Oral Implants Res 1999;10:459-467.

8. Norton MR, Gamble C. Bone classification: an objective scale of bone density using the computerized tomography scan. Clin Oral Implants Res 2001;12:79-84.

9. Spin-Neto R, Stavropoulos A, Dias Pereira LA, Marcantonio E, Jr., Wenzel A. Fate of autologous and fresh-frozen allogeneic block bone grafts used for ridge augmentation. A CBCT-based analysis. Clin Oral Implants Res 2013;24:167-173.

10. Veltri $M$, Ferrari $M$, Balleri P. Correlation of radiographic fractal analysis with implant insertion torque in a rabbit trabecular bone model. Int J Oral Maxillofac Implants 2011;26:108-114.

11. Onem E, Baksi BG, Sogur E. Changes in the fractal dimension, feret diameter, and lacunarity of mandibular alveolar bone during initial healing of dental implants. Int J Oral Maxillofac Implants 2012;27:1009-1013.

12. Heo MS, Park KS, Lee SS, Choi SC, Koak JY, Heo SJ, et al. Fractal analysis of mandibular bony healing after orthognathic surgery. Oral Surg Oral Med Oral Pathol Oral Radiol Endod 2002;94:763-767.

13. Jolley L, Majumdar S, Kapila S. Technical factors in fractal analysis of periapical radiographs. Dentomaxillofac Radiol 2006;35:393-397.

14. Bollen AM, Taguchi A, Hujoel PP, Hollender LG. Fractal dimension on dental radiographs. Dentomaxillofac Radiol 2001;30:270-275.

15. Demirbas AK, Ergun S, Guneri P, Aktener BO, Boyacioglu H. Mandibular bone changes in sickle cell anemia: fractal analysis. Oral Surg Oral Med Oral Pathol Oral Radiol Endod 2008;106:e41-e48.

16. Tosoni GM, Lurie AG, Cowan $A E$, Burleson JA. Pixel intensity and fractal analyses: detecting osteoporosis in perimenopausal and postmenopausal women by using digital panoramic images. Oral Surg
Oral Med Oral Pathol Oral Radiol Endod 2006;102:235-241.

17. Zeytinoglu $M$, Ilhan B, Dundar N, Boyacioglu H. Fractal analysis for the assessment of trabecular peri-implant alveolar bone using panoramic radiographs. Clin Oral Investig; 2014. [Epub ahead of print DOI: 10.1007/s00784-014-1245-y].

18. Sogur E, Baksi BG, Grondahl HG, Sen BH. Pixel intensity and fractal dimension of periapical lesions visually indiscernible in radiographs. J Endod 2013;39:16-19.

19. Mu TJ, Lee DW, Park KH, Moon IS. Changes in the fractal dimension of peri-implant trabecular bone after loading: a retrospective study. $J$ Periodontal Implant Sci 2013;43:209-214.

20. Baksi BG, Fidler A. Fractal analysis of periapical bone from lossy compressed radiographs: a comparison of two lossy compression methods. J Digit Imaging 2011;24:993-998.

21. Huang $\mathrm{CC}$, Chen $\mathrm{JC}$, Chang $\mathrm{YC}$, Jeng $\mathrm{JH}$, Chen $\mathrm{CM}$. A fractal dimensional approach to successful evaluation of apical healing. Int Endod $J$ 2013;46:523-529.

22. Baksi BG, Fidler A. Image resolution and exposure time of digital radiographs affects fractal dimension of periapical bone. Clin Oral Investig 2012;16:1507-1510.

23. Sindeaux R, Figueiredo PT, de Melo NS, Guimaraes AT, Lazarte L, Pereira $\mathrm{FB}$, et al.. Fractal dimension and mandibular cortical width in normal and osteoporotic men and women. Maturitas 2014;77:142-148.

24. Oliveira ML, Pedrosa EF, Cruz AD, Haiter-Neto F, Paula FJ, Watanabe $\mathrm{PC}$. Relationship between bone mineral density and trabecular bone pattern in postmenopausal osteoporotic Brazilian women. Clin Oral Investig 2013;17:1847-1853.

25. Amer ME, Heo MS, Brooks SL, Benavides E. Anatomical variations of trabecular bone structure in intraoral radiographs using fractal and particles count analyses. Imaging Sci Dent 2012;42:5-12.

Received October 22, 2014

Accepted December 11, 2014 